\title{
Health-related Quality of Life (HRQoL) of Individuals from Pune city after 6 weeks of Mild and Moderate grade COVID-19 infec- tion
}

\section{Aditi Soman ${ }^{* 1}$, Aditee Mangaonkar ${ }^{2}$.}

${ }^{* 1}$ Assistant professor, Department of Cardiovascular and Respiratory Physiotherapy, Deccan Education Society's Brijlal Jindal College of Physiotherapy, Pune, Maharashtra (INDIA).

${ }^{2}$ Final BPTh student, Deccan Education Society's Brijlal Jindal College of Physiotherapy, Pune, Maharashtra (INDIA).

\section{ABSTRACT}

Background: Coronavirus disease (COVID-19) caused by SARS-CoV-2 virus was declared as a global pandemic by the WHO in March 2020. India is the second worst hit by the pandemic in which Maharashtra records highest number of infected cases in the country with Pune topping the count. Prevalence of Mild and Moderate grade of COVID-19 infection is high among the population. HRQoL was found to be curtailed in adults who suffered from Upper respiratory tract infection and also in survivors of H1N1 pandemic, SARS and MERS epidemics.

Purpose of study: Alteration in individual's HRQoL can affect his daily activities and community participation. There is a dearth of studies about the impact of COVID-19 infection on the quality of life of patients in Indian Population. Hence, the following study was undertaken and HRQoL was assessed using components of Short Form-12 questionnaire.

Results and main findings: This cross-sectional study was carried out on 121 individuals across Pune city, after a mean of 45 days after suffering from Mild (73\%) or Moderate (27\%) grade of COVID-19 infection. Out of the study population, $29 \%$ had one or more co-morbidities present such as type 2 diabetes mellitus, systemic hypertension, hypothyroidism. Results of the components of the SF-12 questionnaire of these individuals are as follows. $61.15 \%$ of the study population have no limitations in physical functioning, $65 \%$ have no limitation in role physical activities, $72.7 \%$ have no pain interference in their daily activities, $92.6 \%$ have positive general health perception, $90 \%$ have good amount of energy in their daily life, $89.2 \%$ have no significant interference in their social activities, $74 \%$ have no limitations in their daily activities due to their emotional health, $72.7 \%$ have felt peaceful for significant amount of the time and $64.9 \%$ individuals have not felt depressed or sad since the infection.

Conclusion: Health-related Quality of Life is not impaired in $61.15 \%$ of the population of Pune city who suffered from mild and moderate grade COVID-19 infection.

Clinical implication: This study can be helpful in planning a multidisciplinary treatment after 6 weeks of the infection for individuals who were mildly or moderately infected by COVID-19.

KEY WORDS: Covid-19, Health related quality of life, SF-12, persistent symptoms.

Address for correspondence: Dr Aditi Laukik Soman (PT), Deccan Education Society's Brijlal Jindal College of Physiotherapy, Fergusson College Campus, Shivajinagar, Pune-411004, Maharashtra (INDIA). Telephone: 020-67656474 E-Mail: aditi.soman@despune.org
Access this Article online
Journal Information

Quick Response code

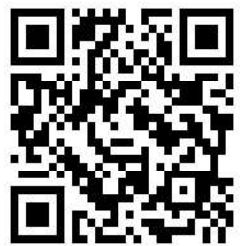

DOI: $10.16965 /$ ijpr.2020.187

International Journal of Physiotherapy and Research

ISSN (E) 2321-1822 | ISSN (P) 2321-8975 https://www.ijmhr.org/ijpr.html

DOI-Prefix: https://dx.doi.org/10.16965/ijpr

\section{Article Information}

Received: 20 Nov 2020

Peer Review: 20 Nov 2020

Revised: 29 Dec 2020
Accepted: 31 Dec 2020

Published (O): 11 Jan 2021

Published (P): 11 Feb 2021 


\section{INTRODUCTION}

Coronavirus disease (COVID-19) is caused by SARS-CoV-2(Severe Acute Respiratory Syndrome Coronavirus 2) virus which is a new coronavirus that emerged in Wuhan, China in December 2020 [1-3]. On January 30, 2020, the World Health Organization (WHO) declared it as a Public Health Emergency of International Concern, and on March 11, a global pandemic was declared [4]. India reported its first case on 30 January 2020 in Thrissur, Kerala having its origin from China [5]. Since March 2020, the country saw an exponential growth in COVID-19 positive cases and recorded close to 1 Million daily positive cases in September 2020. The country peaked in September [6] and there was a decrease in the rate of confirmed cases till the time of writing. India is the second worst hit by the pandemic and counts 8.5 million infected cases at the time of writing [7].

SARS-CoV-2 is highly contagious and is similar to the SARS and MERS virus in nature [8]. However, the case fatality rate of SARS-CoV-2 is lower than that of SARS and MERS even with high transmissibility $[9,10]$.

The most common COVID-19 symptoms tend to appear in about 2 to 14 days after virus exposure and these individuals can present with a wide clinical spectrum ranging from asymptomatic case to septic shock and multiorgan dysfunction [11]. The clinical classification of COVID-19 is primarily divided into mild, normal, severe and critical, based on clinical symptoms, clinical indicators, and imaging $[2,12]$. McGoogan and Wu reported that $81 \%$ cases were mild, $14 \%$ were severe and $5 \%$ were critical in nature [13].

Prevalence of symptoms in non-critical disease is fever $(71.2 \%)$, cough $(56.7 \%)$, sputum production (31.4\%), fatigue (34.5\%) and/or shortness of breath (13.3\%) [9]. Mild Disease Patients may present with symptoms of an upper respiratory tract viral infection which can progress over a week. These include dry cough, mild fever, nasal congestion, sore throat, headache, muscle pain, fatigue, hypo/anosmia $[11,14]$, hypogeusia/ageusia (loss of taste) $[12,15]$. It is also characterized by the absence of serious symptoms such as dyspnoea. They can be managed at COVID Care Centres or at home [16]. In Moderate Disease the patients present with respiratory symptoms of cough, shortness of breath, and tachypnoea, loss of appetite, diarrhoea [17]. Machhi J, et.al found out that symptoms such as headache, nausea, and dizziness and features of mild disease may also be present [2]. These patients can be managed at home or in general wards of the hospital not requiring any external ventilatory assistance [16]. Whereas, in Severe Disease, patients have pneumonia, emergency signs of respiratory failure, severe hypoxaemia, acute respiratory distress syndrome (ARDS), coagulopathies, sepsis, or septic shock. Even in severe forms of the disease, fever can be absent or moderate $[16,18]$. In addition, $5 \%$ of patients can develop a critical disease with features of respiratory failure, Anaemia, cardiac injury, septic shock, Pulmonary embolism, cerebrovascular disease, Guillain Barre syndrome, Meningoencephalitis, Acute heart failure, Renal failure or multiple organ dysfunction. COVID-19 is a systemic disease that can affect beyond the lungs by bloodbased dissemination to multiple organs such as the kidney, liver, muscles, nervous system, and spleen [2].

Patients with pre-existing comorbidities have a higher case fatality rate. These comorbidities include diabetes (7.3\%), respiratory disease (6.5\%), cardiovascular disease $(10.5 \%)$, hypertension (6\%), and oncological complications (5.6\%). Patients without comorbidities have a lesser case fatality rate $(0.9 \%)$ [2].

There are various scales available for grading the severity of COVID-19 infection. The ordinal scale prepared by the WHO measures the patient's clinical status at a particular time during the infection [19].

There are differences in the severity of the symptoms in the Indian population due to various factors such as age, genetics, mutations of cov-2, climate, inherent immunity, race and ethnicity [20-22]. Maharashtra records highest number of infected cases in the country (1.7 million) with Pune topping the daily infection count in September 2020 by recording highest single-day spike of 4935 
cases [23]. COVID-19 related mortality appears to be lower in the health and resource challenged densely populated country like India [24,25].

After recovering from COVID-19 infection, there are persistent symptoms most likely fatigue, shortness of breath, psychological distress which may last after 2-3months [26-29]. Various studies show that healthrelated Quality of Life was poor among COVID-19 patients at 1-month follow-up $[30,31]$. Previous studies on survivors of SARS and MERS have determined that the lung function, exercise capacity is impaired along with psychological impairment even after 1 year $[32,33]$. However, the severe cases of MERS reported quality of life was highly affected than mild cases of MERS [34]. The 2009 H1N1 pandemic also had a significant but temporary impact on the health-related quality of life of the majority of the infected patients [35]. HRQOL was also found to be curtailed in the adults who suffered from Upper respiratory tract infection [36]. Thus, long term outcomes in mild and moderate COVID-19 survivors also can be anticipated. Increase in severity of symptoms can be associated with decrease in almost all aspects of patients' QOL.

WHO defines Quality of Life as an individual's perception of their position in life in the context of the culture and value systems in which they live and in relation to their goals, expectations, standards and concerns [37]. Quality of life (QoL) is widely used as a powerful tool to evaluate an individual's holistic health condition and well-being. Health related quality of life (HRQoL) is a part of the patient's overall quality of life that will represent the multi-dimensional functional effect of an illness and its therapy upon the patient and it's perception by the patient. Alteration in HRQoL can affect either mental or physical well-being at individual level and at community level [38]. Other factors that can affect the HRQoL are patient education and awareness, symptoms of the illness, adverse drug reactions, economical condition, treatment and social and cultural factors [39]. A good quality of life determines good well-being of the patient and is associated with healthy behaviour, life satisfaction, better productivity social participation and more contribution towards the community [40].

The SF-12, a self-reported outcome measure that assesses the impact of health on an individual's everyday life, is a shortened version of its predecessor, the SF-36, which itself evolved from the Medical Outcomes Study. The components from the standard version of the SF-12 is used to assess the health related-QoL after 6 weeks of mild and moderate grade of COVID-19 infection [41].

Need of Study: There are limited studies about the impact of Mild and Moderate grade of COVID-19 infection on the quality of life of patients in Indian Population. Alteration of individual's HRQoL can affect his participation in daily activities of self-care, job related activities and social/ leisure activities. Therefore, it is important to assess these HRQoL aspects in patients suffered from mild and moderate grade COVID-19 infection to know if any individual is in need of further assessment and strategies to improve their well-being.

Aim of the study: To assess the Health-related Quality of Life (HRQoL) of Individuals from Pune city after 6 weeks of Mild and Moderate grade COVID-19 infection.

\section{Objectives:}

1. To assess the HRQoL of individuals from Pune city after 6 weeks of Mild grade COVID-19 infection using components of SF-12.

2. To assess the HRQoL of individuals from Pune city after 6 weeks of Moderate grade COVID19 infection using components of SF-12.

\section{Inclusion Criteria:}

1. Males and females between age group of 18 to 60 years

2. Individuals who had tested positive for COVID19 by RT-PCR test before 6 weeks.

3. Individuals who have completed treatment by expert doctors for the symptoms of mild and moderate grade COVID-19 infection.

4. Individuals tested negative or now asymptomatic post treatment.

\section{Exclusion Criteria:}

1. Individuals who were on Mechanical Venti 
latory Assistance during their period of hospitalisation.

2. Individuals having any known Respiratory Condition other than COVID-19.

3. Individuals having any known Neurological or Psychiatric disorders.

4. Individuals who underwent any major surgery in the past 2 years.

\section{METHODS}

The study was approved by the Institutional Ethical Committee. Permission from the Administration In-charge of the COVID Care Centre at Pune was sought. A cross-sectional study was carried out from August to October 2020 on individuals, who had tested positive for mild or moderate grade of COVID-19 infection during the period of June to September 2020, to assess the HRQoL Pune, India. Individuals fulfilling the inclusion criteria were identified. Verbal consent was taken from the study participants over the telephone call.

A Telephonic Interview of 121 individuals $(\mathrm{N}=121)$ was conducted which comprised of demographic details, medical history, level of physical activity, present health condition and the SF-12 Questionnaire. The scale was interpreted according to the norms.

Data was collected and descriptive statistics was performed.

\section{Operational definition-}

1) Mild and Moderate grade infection- as specified by the ordinal scale of $\mathrm{WHO}^{13}$

2) No impairment of $\mathrm{HRQOL}=$ Percentage Population for individual component of SF- $12>50 \%$

\section{RESULTS AND DISCUSSION}

The minimum required sample size for estimation of score for Indian Patients is 106, considering mean score of 50 and standard deviation of 10 at type 1 error alpha of 0.001 and allowable error of $5 \%$. However, data was collected from 121 individuals ( $N=121)$ who passed the inclusion criteria after an average of 45 days from onset of infection. Table 1 shows the demographic characteristics of the study. Study participants consisted of 66 (55\%) females and 55 (45\%) males ageing between
Table 1: Demographic Characteristics of study population.

\begin{tabular}{|c|c|c|c|}
\hline Sr. No. & Parameter & Subtype & $\begin{array}{l}\text { Percentage } \\
\text { Value (\%) }\end{array}$ \\
\hline \multirow{4}{*}{1} & \multirow{4}{*}{$\begin{array}{c}\text { Age Distribution Mean } \\
\text { age }=41.5 \text { years } \\
\text { (refer graph 1.1) }\end{array}$} & $20-30(n=27)$ & 22 \\
\hline & & $31-40(n=29)$ & 24 \\
\hline & & $41-50(n=34)$ & 28 \\
\hline & & $51-60(n=31)$ & 26 \\
\hline \multirow{2}{*}{2} & \multirow{2}{*}{ Sex (ref graph 1.2) } & Male $(n=55)$ & 45 \\
\hline & & Female $(n=66)$ & 55 \\
\hline \multirow{2}{*}{3} & \multirow{2}{*}{$\begin{array}{l}\text { Morbidity profile } \\
\text { (ref graph 1.3) }\end{array}$} & Co-morbidity present $(n=35)$ & 29 \\
\hline & & $\begin{array}{l}\text { No co-morbidity present } \\
\qquad(\mathrm{n}=86)\end{array}$ & 71 \\
\hline \multirow{6}{*}{4} & \multirow{6}{*}{$\begin{array}{l}\text { Co-morbidity Distribution } \\
\text { (ref graph 1.3) }\end{array}$} & Diabetes Mellitus( $(n=12)$ & 10 \\
\hline & & $\begin{array}{c}\text { Systemic } \\
\text { Hypertension( } n=16)\end{array}$ & 13 \\
\hline & & $D M+H T N(n=3)$ & 2 \\
\hline & & Hypothyroidism(n=3) & 3 \\
\hline & & Hypothyroid $+H T N(n=1)$ & 1 \\
\hline & & None $(n=86)$ & 71 \\
\hline \multirow{2}{*}{5} & \multirow{2}{*}{$\begin{array}{c}\text { Grade of COVID-19 infection } \\
\text { (ref graph 1.4) }\end{array}$} & Mild $(n=88)$ & 73 \\
\hline & & Moderate $(n=33)$ & 27 \\
\hline
\end{tabular}

Graph 1.1

Age-wise Distribution of study population

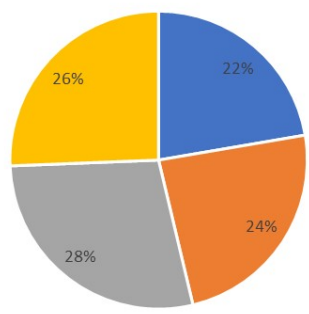

- 20-30

$=31-40$

$=41-50$

- $51-60$

Graph 1.2

Sex distribution of study population

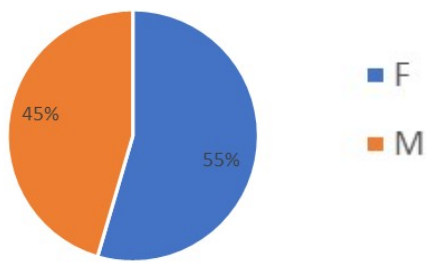

Graph 1.3

Co-morbidity distribution in study population

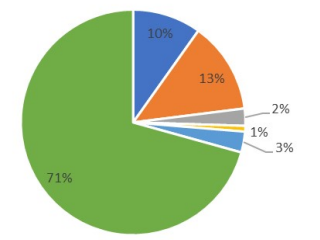

Graph 1.4

Grading of COVID-19 infection in the study population

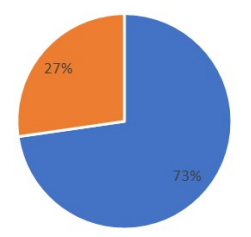

- Mild = Moderate 
Table 2: Physical symptoms as reported by Individuals (a) during Acute COVID-19 infection, (b) 6 weeks after infection.

\begin{tabular}{|c|c|c|c|c|}
\hline \multicolumn{5}{|c|}{$N=121$} \\
\hline \multirow[t]{2}{*}{ Symptom } & \multicolumn{2}{|c|}{$\begin{array}{l}\text { (a) Acute COVID-19 } \\
\text { (graph 2.1) }\end{array}$} & \multicolumn{2}{|c|}{$\begin{array}{l}\text { (b) After } 6 \text { weeks of } \\
\text { infection (graph 2.2) }\end{array}$} \\
\hline & $\mathbf{n}$ & $\%$ & $\mathbf{n}$ & $\%$ \\
\hline Fever & 83 & $69 \%$ & 0 & 0 \\
\hline Fatigue & 74 & $61 \%$ & 38 & $31 \%$ \\
\hline cough & 42 & $35 \%$ & 9 & $7 \%$ \\
\hline Loss of Appetite & 3 & $2 \%$ & 0 & 0 \\
\hline Body ache & 28 & $23 \%$ & 4 & $3 \%$ \\
\hline Sore throat & 9 & $7 \%$ & 0 & $0 \%$ \\
\hline breathlessness & 24 & $20 \%$ & 20 & $17 \%$ \\
\hline Headache & 14 & $12 \%$ & 2 & $2 \%$ \\
\hline Nasal congestion & 17 & $14 \%$ & 0 & $0 \%$ \\
\hline nausea & 3 & $2 \%$ & 0 & $0 \%$ \\
\hline Loss of Smell & 24 & $20 \%$ & 0 & $0 \%$ \\
\hline Loss of Taste & 11 & $9 \%$ & 0 & $0 \%$ \\
\hline Dizziness & 3 & $2 \%$ & 1 & $1 \%$ \\
\hline Leg Pain & 3 & $2 \%$ & 13 & $11 \%$ \\
\hline Chest Pain & 1 & $1 \%$ & 4 & $3 \%$ \\
\hline Joint pain & 0 & $0 \%$ & 1 & $1 \%$ \\
\hline None & 4 & $3 \%$ & 68 & $56 \%$ \\
\hline
\end{tabular}

Graph 2: Comparison of symptoms in acute phase and 6 weeks after infection.

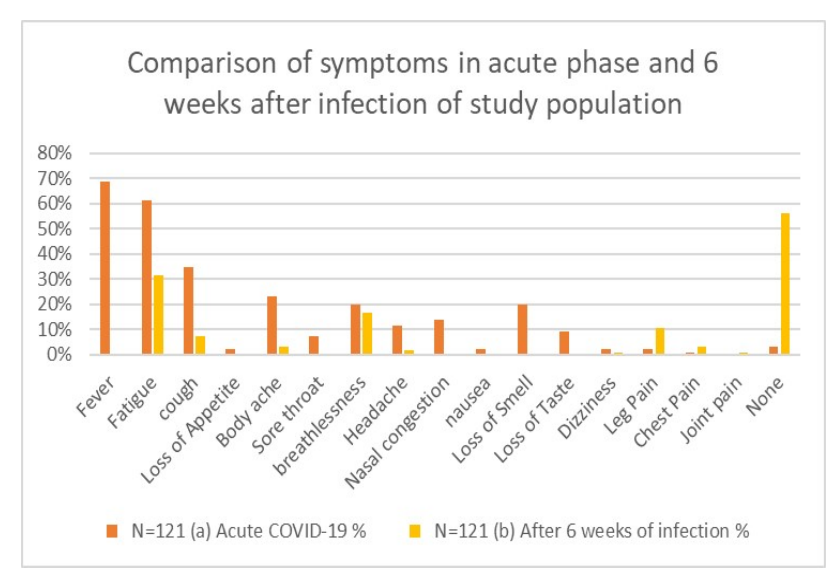

Graph 3.1

Moderate Activities

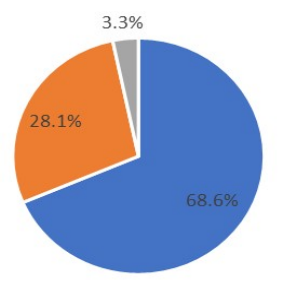

- no

- yes,limited a little

nes,limited a lot

\section{Graph 3.3}

Role Physical-accomplished less

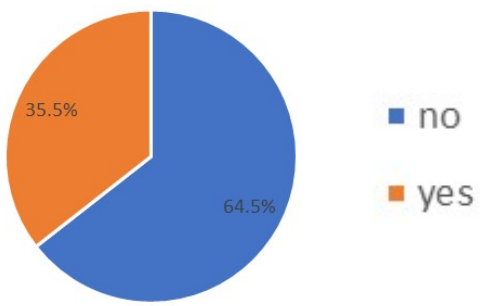

Table 3: SF-12 Interpretation.

\begin{tabular}{|c|c|c|c|c|}
\hline \multicolumn{5}{|c|}{$\mathrm{N}=121$} \\
\hline S.no. & Item & Ans & Value & $\begin{array}{c}\text { Value } \\
\text { Percentage }\end{array}$ \\
\hline & Physical Summary Component & & & \\
\hline \multirow[t]{2}{*}{1} & Physical Functioning & & & \\
\hline & & No & 83 & $68.60 \%$ \\
\hline \multirow[t]{3}{*}{ a } & Moderate Activities (ref. graph 3.1) & Yes, limited a little & 34 & $28.10 \%$ \\
\hline & & Yes, limited a lot & 4 & $3.30 \%$ \\
\hline & & No & 65 & $53.70 \%$ \\
\hline \multirow[t]{2}{*}{ b } & Climbing stairs (graph 3.2) & Yes, limited a little & 48 & $39.70 \%$ \\
\hline & & Yes, limited a lot & 8 & $6.60 \%$ \\
\hline 2 & Role-physical & & & \\
\hline \multirow{2}{*}{ a } & Accompliched less 1 aranh 33 & No & 78 & $64.50 \%$ \\
\hline & Accompisned less (grapn 3.3$)$ & Yes & 43 & $35.50 \%$ \\
\hline \multirow{2}{*}{ b } & limitod in itc hind $/ 2 n$ h 2 & No & 79 & $65.30 \%$ \\
\hline & LImited in its KInd (graph 3.4) & Yes & 42 & $34.70 \%$ \\
\hline \multirow{5}{*}{3} & & Not at all & 88 & $72.70 \%$ \\
\hline & & A little bit & 19 & $15.70 \%$ \\
\hline & Bodily Pain (graph 3.5) & Moderately & 8 & $6.60 \%$ \\
\hline & & Quite a bit & 5 & $4.10 \%$ \\
\hline & & Extremely & 1 & $0.80 \%$ \\
\hline \multirow{5}{*}{4} & & Excellent & 26 & $21.50 \%$ \\
\hline & & Very good & 45 & $37.20 \%$ \\
\hline & General Health (graph 3.6) & Good & 41 & $33.90 \%$ \\
\hline & & Fair & 9 & $7.40 \%$ \\
\hline & & Poor & 0 & $0.00 \%$ \\
\hline & Mental Component Summary & & & \\
\hline \multirow{6}{*}{5} & \multirow{6}{*}{ Vitality (graph 3.7) } & All of the time & 39 & $32.20 \%$ \\
\hline & & Most of the time & 50 & $41.30 \%$ \\
\hline & & A good bit of the time & 20 & $16.50 \%$ \\
\hline & & Some of the time & 7 & $5.80 \%$ \\
\hline & & A little of the time & 4 & $3.30 \%$ \\
\hline & & None of the time & 1 & $0.80 \%$ \\
\hline \multirow{5}{*}{6} & \multirow{5}{*}{ Social functioning (graph 3.8) } & All of the time & 7 & $5.80 \%$ \\
\hline & & Most of the time & 6 & $5.00 \%$ \\
\hline & & Some of the time & 17 & $14.00 \%$ \\
\hline & & A little of the time & 17 & $14.00 \%$ \\
\hline & & None of the time & 74 & $61.20 \%$ \\
\hline 7 & Role-emotional & & & \\
\hline \multirow{2}{*}{ a } & \multirow{2}{*}{ Accomplished less (graph 3.9) } & No & 89 & $73.60 \%$ \\
\hline & & Yes & 32 & $26.40 \%$ \\
\hline \multirow{2}{*}{ b } & \multirow{2}{*}{ Not Careful (graph 3.10) } & No & 90 & $74.40 \%$ \\
\hline & & Yes & 31 & $25.60 \%$ \\
\hline 8 & Mental Health & & & \\
\hline \multirow{6}{*}{ a } & \multirow{6}{*}{ Peaceful (graph 3.11) } & All of the time & 32 & $26.40 \%$ \\
\hline & & Most of the time & 40 & $33.10 \%$ \\
\hline & & A good bit of the time & 16 & $13.20 \%$ \\
\hline & & Some of the time & 22 & $18.20 \%$ \\
\hline & & A little of the time & 9 & $7.40 \%$ \\
\hline & & None of the time & 2 & $1.70 \%$ \\
\hline \multirow{6}{*}{ b } & & All of the time & 1 & $0.80 \%$ \\
\hline & & Most of the time & 10 & $8.30 \%$ \\
\hline & Blue/sad (graph 3.12) & A good bit of the time & 6 & $5.00 \%$ \\
\hline & & Some of the time & 23 & $19.00 \%$ \\
\hline & & A little of the time & 34 & $28.10 \%$ \\
\hline & & None of the time & 47 & $38.80 \%$ \\
\hline
\end{tabular}

\section{Graph 3.2}

Climbing stairs

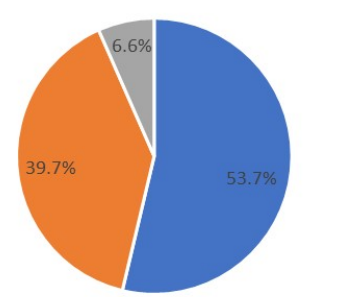

no

yes,limited a little

- yes,limited a lot

\section{Graph 3.4}

Role Physical-limited in its kind

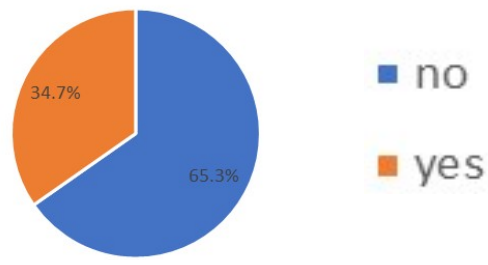


Graph 3.5

Pain Interfere

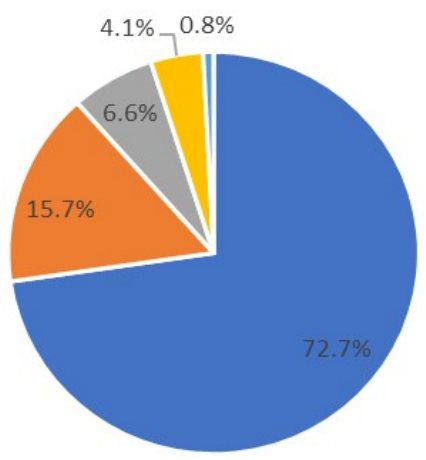

not at all

- a little bit

moderately

= quite a bit

- extremely

\section{Graph 3.7}

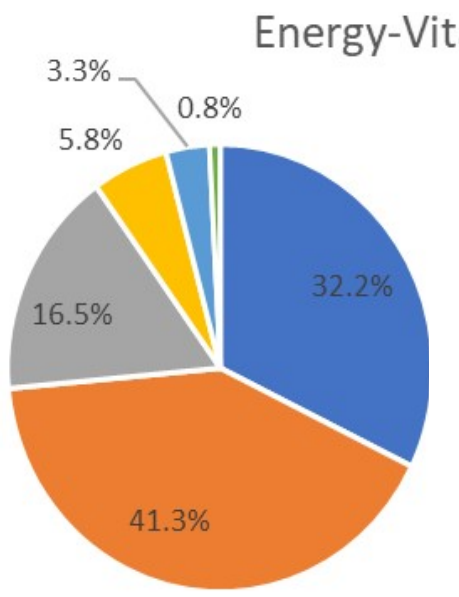

\section{Graph 3.9}

Role emotional-accomplised less

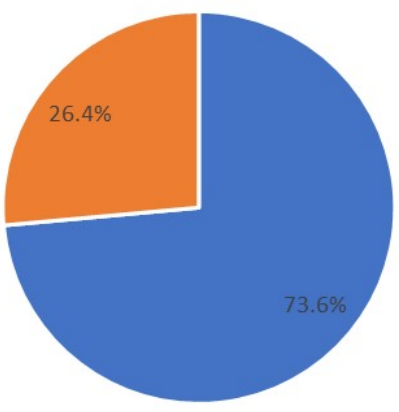

- all of the time

- most of the time

- a good bit of the time

" some of the time

- a little of the time

- none of the time

- no

- yes

\section{Graph 3.11}

Mental Health-Peaceful

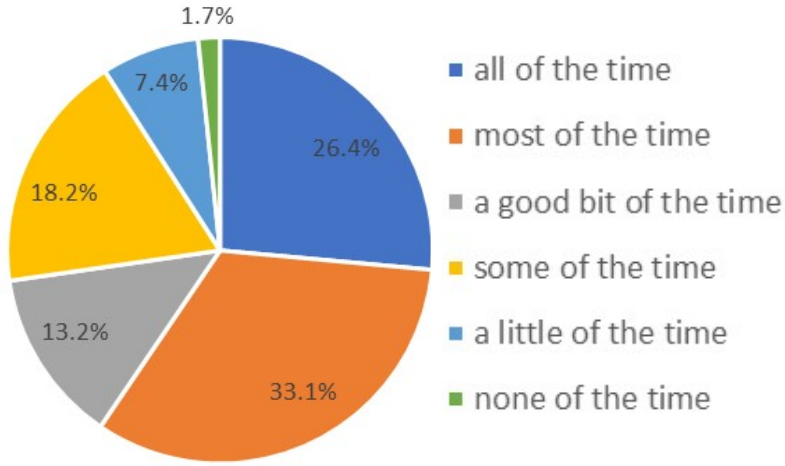

\section{Graph 3.6}

EVGFP Rating- Health perception

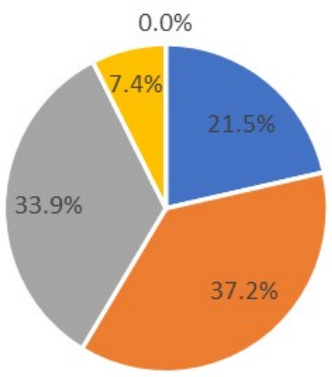

- excellent " very good " good " fair " poor

\section{Graph 3.8}

Social Time Interference

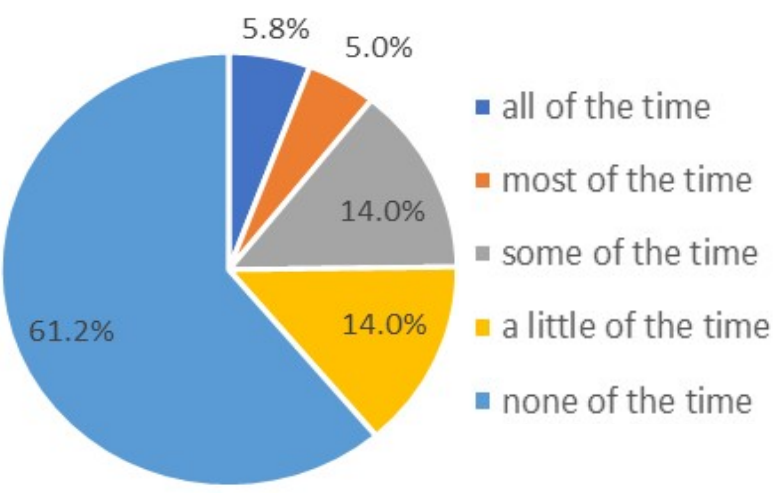

Graph 3.10

Role Emotional-Not careful

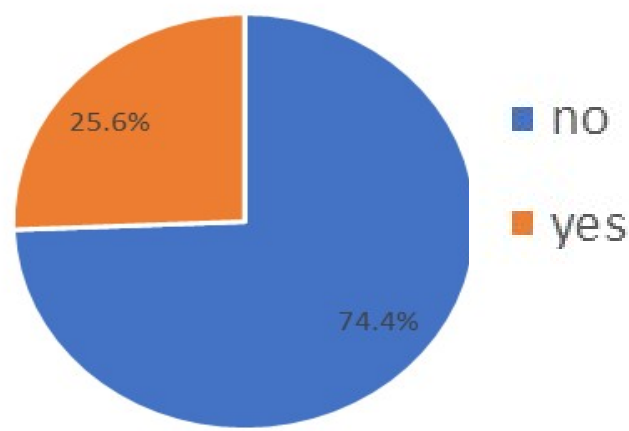

Graph 3.12

Mental Health-Blue/Sad

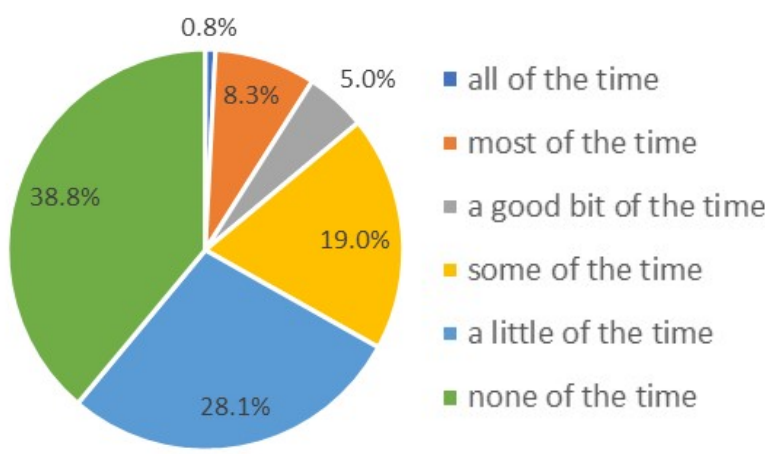


18 to 60 years showing female predominance (graph 1.2). The Mean age was 41.5 years. 35 of the individuals (29\%) had one or more co-morbidities present such as Type 2 diabetes mellitus, systemic hypertension, hypothyro-idism. The prevalence of co-morbidities increased in 41-60 age group (graph 1.3) [2].

The Clinical Characteristics of the study population are shown in Table 2. Out of 121 individuals, 88 (73\%) were mildly infected and $33(27 \%)$ were Moderately infected (graph 1.4). The ordinal scale prepared by the WHO for assessing the clinical progression of the illness over a period of time was used to grade the study individuals according to the patient's status [13]. 97\% Individuals reported having symptoms during the Acute period of Covid19 infection as denoted in Table 2(a). Fever (69\%), Fatigue (61\%), cough (35\%), body ache $(23 \%)$, breathlessness (20\%), anosmia (20\%), nasal congestion (14\%), ageusia (9\%), sore throat $(7 \%)$ were the majorly reported symptoms by the individuals during the Acute infection. $2 \%$ individuals reported having dizziness, leg pain, nausea and loss of appetite too. (graph 2). After a mean of 45 days, $56 \%$ individuals did not report any persistent symptom whereas out of the remaining $44 \%$, the most frequently reported symptom was fatigue (31\%) followed by Breathlessness (17\%), leg pain (11\%), cough $(7 \%)$, body ache $(3 \%)$, chest pain $(3 \%)$, joint pain $(3 \%)$, headache(2\%), Dizziness(1\%) (Table 2(b)).

In the comparison seen in graph 2, symptoms such as Fever, anosmia, ageusia, nausea, loss of appetite, sore throat are completely absent after 6 weeks of infection. It can be seen that there is significant decrease in the persistence of symptoms like fatigue, cough, body ache and headache, dizziness. However, the prevalence of breathlessness has reduced only by $3 \%$ after 6 weeks of the infection. $4 \%$ of the individuals who had breathlessness during Acute period of infection had persistent breathlessness even after 6 weeks and the remaining $12 \%$ have developed breathlessness over the period of 6 weeks. A significant rise in the occurrence of Leg pain, chest pain and joint pain after 6 weeks of infection is noted. (Table 2) Persistence of above symptoms can be because of post-viral fatigue [42], postviral arthropathy, or lack of mobility during the acute phase of infection and even after 6 weeks of infection in mild cases and lung impairment affecting the oxygenation in moderate cases. Lack of knowledge of exercises during and after infection can be the reason for persistent symptoms even after 6 weeks of mild and moderate COVID-19 infection.

The SF-12 questionnaire was administered to assess the HRQoL of the study population. It consists of 2 summary measures- Physical component summary (PCS-12) and Mental Component Summary (MCS-12). The PCS-12 consists of general health, bodily pain, physical functioning and role-physical scales. Whereas the MCS-12 consists of vitality, role-emotional, mental health and social functioning scales (Table 3 ).

In this study, $61.1 \%$ individuals have no limitation in performing physical activities because of their present health condition. $68.6 \%$ individuals have no limitation in doing moderate activities such as pulling, pushing, moving a table, lifting light weights, daily chores. $28.1 \%$ have little limitation in performing such moderate activities and 3.3\% have a lot limitation in executing such activities (graph 3.1). $53.7 \%$ individuals have certainly no limitation in climbing stairs. Out of the remaining $46.3 \%$ results $39.7 \%$ individuals complained of having minor limitation while climbing stairs whereas $6.6 \%$ individuals had very much limitation while climbing several flights of stairs after suffering from COVID-19 infection (graph 3.2). These individuals complained of experiencing shortness of breath, fatigue or leg cramps after climbing stairs or doing moderate intensity physical activities. Some individuals would avoid doing these activities due to fear of developing symptoms like dyspnoea. It was found that $65 \%$ of the individuals had no limitation in role-physical activities, i.e. their work or other regular daily activities because of health problems. This number can be overestimated because of the new normal way of working from home and added restrictions of movement thereby 
demanding less physical activity than usual in certain number of cases. Out of the remaining population, $35.5 \%$ individuals feel that they have accomplished less work than usual because of their physical health problems (graph 3.3), whereas $34.7 \%$ individuals feel their work is limited in its kind it used to be (graph 3.4). Bodily pain was not predominating in the study population. $72.7 \%$ individuals did not complain of any kind of pain that would interfere with their normal work that includes household and outside work. In the remaining $27.3 \%$ individuals ranging from little interference to extreme interference, $15.7 \%$ had little interference of bodily pain in their regular work and $0.8 \%$ had extreme interference (graph 3.5).

Increase in the prevalence of symptoms such as leg pain, chest pain, joint pain after 6 weeks of infection resulted in the interference with their regular work. The general health perception was high towards the positive side (58.7\%). $21.5 \%$ individuals felt they have an excellent health with $37.2 \%$ considering very good health and $33.9 \%$ agreeing they have good health. Only $7.4 \%$ individuals have complained of having fair health status due to their physical, mental and social wellbeing. (Graph 3.7)

In the MCS scale, the Vitality of the individuals is represented in Graph 3.8. 32.2\% individuals have had lot of energy all of the time whereas, $41.3 \%$ individuals have had significant amount of energy most of the time. $16.5 \%$ individuals had energy for a good bit of the time, $9.2 \%$ felt energetic some or little of the time while $0.8 \%$ felt no energy at any point of the time. Prevalence of fatigue during and after the infection, reduced physical activity, lack of motivation, depression, stress can justify the reduced vitality in COVID-19 survivors. The impact of lockdown in India since March 2020 and fear, anxiety associated with the infectious disease and its outcome, loss of employment due to the pandemic has affected the mental health as well as the social life of the people. Stress, depression, irritability and boredom due to the isolation and quarantine can affect the mental health and quality of life of these individuals [43]. The stigma associated with the novel disease has led to those affected with the virus suffer. The limitations in the usual role-activities due to emotional problem or mental health were observed in only $26 \%$ of the study population. $73.6 \%$ individuals did not face any problem because of anxiety, stress or depression in accomplishing their regular tasks as usual but $26.4 \%$ individuals encountered this issue after the infection (graph 3.9).

$25.6 \%$ individuals have been less careful in carrying out their regular work because of anxiety or feeling depressed (graph 3.10). In terms of feeling peaceful, only $26.4 \%$ individuals felt calm and peaceful all of the time, $33.1 \%$ individuals feeling the same most of the time and $13.2 \%$ feeling calm a good bit of their time. $25.6 \%$ individuals believed to be peaceful some or little amount of time and only $1.7 \%$ individuals did not feel peaceful any of the time since the infection (graph 3.11). 14.1\% individuals reported feeling sad or blue for significant amount of the time. 19\% individuals felt sad for some of the time, $28.1 \%$ a little amount of the time or rarely and $38.8 \%$ individuals did not feel sad or depressed any of the time since the onset of infection (graph 3.12). Patient education, family or social education and awareness about the disease, its outcomes and effective precautionary measures; effective treatment, emotional support and positive attitude were all the reasons described by the individuals for their mental health not being affected due to the novel disease. $61.2 \%$ individuals did not report any interference with their social life because of their physical or emotional health. $14 \%$ of the study population had little or some interference with their social activities respectively. $5 \%$ individuals had a great impact on their social life for most of the time due to their health and 5.8\% individuals reported that all their social activities and well-being was disturbed all of the time since their onset of infection (graph 3.8). They claimed that there was a social stigma regarding being infected with the novel virus and society would avoid interacting with them and would isolate them even after 6 weeks of infection.

The study population was evaluated for their 
level of physical activity before getting infected and after 6 weeks of infection. Majority of the study population i.e. $55 \%$ of the study population would perform some form of cardio exercises before COVID-19 infection. 19\% individuals would perform yogasana and $9 \%$ individuals would practice breathing exercises before the infection. The proportion of performing breathing exercises has increased after the infection to $28 \%$. However, the proportion of individuals not performing any sort of exercise has increased from $37 \%$ to $49 \%$ after the infection. Fear of performing heavy physical activity post-illness, lack of knowledge of physical activity and exercises during and after the infection, prevalence of fatigue, breathlessness and pain, low motivation were a few reasons of individuals not continuing any sort of exercise post-COVID19. 75\% of the study population have resumed their work as usual and returned to previous level of activity. $12 \%$ individuals have resumed their work in the new-normal work from home setting, thus not requiring high physical activity. $13 \%$ individuals have not yet returned to their previous level of physical activity.

Persistence of symptoms after 6 weeks such as leg pain, joint pain, chest pain, and breathlessness are effects of immobility or inactivity during the acute phase as well as after 6 weeks of infection. As reported earlier, lack of exercises can aggravate the symptoms and which may constrain the individuals from performing exercises which results into a vicious cycle. This cycle needs to be broken by medically prescribing exercises and performing exercises under supervision which will help to improve the symptoms and thereby quality of life of such individuals.

Limitations: SF-12 score was not used to depict the actual HRQoL of individuals.

\section{Scope:}

1. Such type of study can be conducted in severe and critically infected COVID-19 patients.

2. Methods other than telephonic survey can be used to conduct this study.

3. A comparative study between the severity of persistent symptoms and HRQoL of COVID19 infected patients can be conducted.

\section{CONCLUSION}

Health-related Quality of Life is not impaired in $61.15 \%$ of the population who suffered from mild and moderate grade COVID-19 infection in Pune city.

Clinical Implication: This study can be helpful in planning a multidisciplinary treatment after 6 weeks of the infection for individuals who were mildly or moderately infected by COVID-19. Awareness regarding the importance of exercises after the acute phase of COVID-19 infection needs to be increased to help relieve post-COVID19 symptoms and improve HRQoL in affected individuals.

\section{ABBREVIATIONS}

HRQoL: Health-related Quality of Life

SF-12: Short form 12 questionnaire

MCS: Mental component summary

PCS: Physical component summary

\section{ACKNOWLEDGEMENTS}

We would like to express a heartfelt gratitude to Mr. Makarand Gokhale, administrative in-charge of the Garware COVID care centre, Pune and Dr Kalyani Sant (BAMS) for their extended co-operation and helping us with the data collection. We would like to express our gratefulness to Dr Swati Raje for assisting with the statistical analysis for this study. We also wish to thank Dr Aparna Sadhale (PT), Principal, DES Brijlal Jindal College of Physiotherapy, Pune for consenting us to conduct this study. We wish to thank our colleagues, Dr Supriya Raikwar (PT), Dr Prajakta Bidkar (PT), Dr Shrikant Sahu (PT), Dr Shrinidhi Kulkarni (PT), Dr Jinal Kothari (PT) who were treating the COVID-19 Infected patients for their support during the data collection from the Sassoon General Hospital, Pune. We would like to thank all the participants of this study for their co-operation and support during this study without whom this study would not have been possible. Lastly, we wish to thank all our colleagues, family and friends who have helped us directly or indirectly in completing this study successfully.

\section{Conflicts of interest: None}




\section{REFERENCES}

[1]. Guqin Zhang, Chang Hu, Linjie Luo, Fang Fang, Yongfeng Chen, $\mathrm{J}$ ianguo $\mathrm{Li}$, et. al Clinical features and outcomes of 221 patients with COVID-19 in Wuhan, China medRxiv 2020.03.02.20030452

[2]. Machhi J, Herskovitz J, Senan AM, et al. The Natural History, Pathobiology, and Clinical Manifestations of SARS-CoV-2 Infections. J Neuroimmune Pharmacol. 2020;15(3):359-386.

[3]. Hussin A.Rothan, Siddappa N.Byrareddy. The epidemiology and pathogenesis of coronavirus disease (COVID-19) outbreak. Journal of Autoimmunity 2020; 109.

[4]. Coronavirus disease (COVID-19) pandemic. https:/ /www.who.int/emergencies/diseases/novelcoronavirus-2019 (accessed).

[5]. David Reid. India confirms its first coronavirus case. https://www.cnbc.com/2020/01/30/india-confirms-first-case-of-the-coronavirus.html (accessed).

[6]. Soutik Biswas. Coronavirus: Has the pandemic really peaked in India? https://www.bbc.com/news/ world-asia-india-54596707 (accessed).

[7]. https://www.coronatracker.com/country/india/ ) CoronaTracker. https://www.coronatracker.com/ country/india/ (accessed).

[8]. Prof Chaolin Huang, MD, Yeming Wang, MD, Prof Xingwang Li, MD, Prof Lili Ren, PhD, Prof Jisnping Zhao, MD, Yi Hu, MD, et. al. Clinical features of patients infected with 2019 novel coronavirus in Wuhan, China. The Lancet 2020; 395(10223)

[9]. Prof Eskiid Peterson, MD, Prof Marion Koopmans, DVM, Unyeong Go, MD, Davidson $\mathrm{H}$ hamer, MD Nicola Petrosillo, et. al. Comparing SARS-CoV-2 with SARS-CoV and influenza pandemics. The Lancet 2020; 20(9)

[10]. Esakandari, H., Nabi-Afjadi, M., Fakkari-Afjadi, J. et al. A comprehensive review of COVID-19 characteristics. Biol Proced Online 2020;22(19).

[11]. Rajesh T. Gandhi, M.D., John B. Lynch, M.D., M.P.H., and Carlos del Rio, M.D. Mild or Moderate COVID19. N Engl J Med 2020; 383:1757-1766.

[12]. Yu-Huan Xu, Jong-Hui Dong, Wei-Min An, Xi Ma, et.al. Clinical and computed tomographic imaging features of novel coronavirus pneumonia caused by SARS-CoV-2. Journal of Infection 2020; 80(4).

[13]. Wu Z, McGoogan JM. Characteristics of and Important Lessons from the Coronavirus Disease 2019 (COVID-19) Outbreak in China: Summary of a Report of 72/ 314 Cases from the Chinese Center for Disease Control and Prevention. JAMA. 2020;323(13):1239-1242.

[14]. G.-u. Kim, M.-J. Kim, S.H. Ra, J. Lee, S. Bae, J. Jung, S.-H. Kim. Clinical characteristics of asymptomatic and symptomatic patients with mild COVID19. Clinical Microbiology and Infection 2020; 26(7):

[15]. Melina Michelen, Nicholas Jones and Charitini Stavropoulou. In patients of COVID-19, what are the symptoms and clinical features of mild and moderate cases? The Centre for Evidence-Based Medicine 2020. https://www.cebm.net/ COVID-19/in-patients-of-COVID-19-what-are-thesymptoms-and-clinical-features-of-mild-and-moderate-case/\#R10

[16]. Clinical Management Protocol:COVID-19; MoHFW, Government of India, version 3 https:// w w w. m o h f w. g o v. i n / pd f / ClinicalManagementProtocolforCOVID19.pdf

[17]. Pan L, Mu M, Yang P, et al. Clinical Characteristics of COVID-19 Patients with Digestive Symptoms in Hubei, China: A Descriptive, Cross-Sectional, Multicenter Study. Am J Gastroenterol. 2020;115(5):766-773.

[18]. Ortiz-Prado E, Simbaña-Rivera K, Gómez-Barreno $L$, et al. Clinical, molecular, and epidemiological characterization of the SARS-CoV-2 virus and the Coronavirus Disease 2019 (COVID-19), a comprehensive literature review. Diagn Microbiol Infect Dis. 2020;98(1):115094.

[19]. WHO R\&D Blueprint ; https://www.who.int/blueprint/priority-diseases/key-action/COVID19_Treatment_Trial_Design_Master_Protocol_synopsis_ Final_18022020.pdf

[20].Chakrabarti Sankha Shubhra, Kaur Upinder, Banerjee Anindita, et al. COVID-19 in India: Are Biological and Environmental Factors Helping to Stem the Incidence and Severity? [J]. Aging and disease, 2020; 11(3): 480-488.

[21]. Priyanka Saha, Arup Kumar Banerjee, Prem Prakash Tripathi, Amit Kumar Srivastava, Upasana Ray; A virus that has gone viral: amino acid mutation in $\mathrm{S}$ protein of Indian isolate of Coronavirus COVID-19 might impact receptor binding, and thus, infectivity. Biosci Rep 29 May 2020; 40 (5): BSR20201312.

[22]. Comparative analyses of SAR-CoV2 genomes from different geographical locations and other coronavirus family genomes reveals unique features potentially consequential to host-virus interaction and pathogenesis; Rahila Sardar, Deepshikha Satish, Shweta Birla, Dinesh Gupta; bioRxiv 2020;03.21.001586.

[23]. Amitabh Sinha, Anuradha Mascarenhas, Ajay Jadhav; Explained: How did Pune top coronavirus count for all of India? https://indianexpress.com/ article/explained/explained-how-pune-toppedcovid-count-6587134/

[24].Vijay KumarJain, Karthikeyan Iyengar, Abhishek Vaish, Raju Vaishya. Differential mortality in COVID19 patients from India and western countries. Diabetes \& Metabolic Syndrome: Clinical Research \& Reviews 2020; 14(5).

[25]. Rajender S. Why India may do much better off with COVID-19. Polymorphism. 2020;4: 53-58.

[26]. Carfi A, Bernabei R, Landi F, for the Gemelli Against COVID-19 Post-Acute Care Study Group. Persistent Symptoms in Patients After Acute COVID19. JAMA. 2020;324(6):603-605. doi:10.1001/ jama.2020.12603 

grade COVID-19 infection.

[27]. Eve Garrigues, Paul Janvier, Yousra Kherabi, Vasco Honsel, Bruno Fantin, Yann Nguyen, et al. Post-discharge persistent symptoms and health-related quality of life after hospitalization for COVID19. Journal of Infection 2020;

[28]. Singh SJ, Barradell A, Greening N, Bolton CE, Jenkins G, Preston L, Hurst JR. The British Thoracic Society survey of rehabilitation to support recovery of the Post Covid -19 population. MedRxiv 2020;

[29]. Stephen J. Halpin, Claire Mclvor, Gemma Whyatt, Anastasia Adams, Olivia Harvey, Lyndsay McLean et. al. Post-discharge symptoms and rehabilitation needs in survivors of COVID-19 infection: A crosssectional evaluation. Journal of Medical Virology 2020. 10.1002/jmv.26368 (accessed).

[30]. Chen K-Y, Li T, Gong F-H, Zhang J-S and Li X-K. Predictors of Health-Related Quality of Life and Influencing Factors for COVID-19 Patients, a Follow-Up at One Month. Front. Psychiatry 2020;11:668.

[31]. Chiara Temperoni, Francesco Barchiesi. Clinical characteristics, management and health-related quality of life in young adults with COVID-19; 12 October 2020, PREPRINT (Version 1) available at Research Square

[32].Ahmed H, Patel K, Greenwood DC, Halpin S, Lewthwaite P, Salawu A, Eyre L, Breen A, O'Connor $R$, Jones $A$, Sivan $M$. Long-term clinical outcomes in survivors of severe acute respiratory syndrome and Middle East respiratory syndrome coronavirus outbreaks after hospitalisation or ICU admission: A systematic review and meta-analysis. J Rehabil Med. 2020 May 31;52(5): jrm00063.

[33]. Hui DS, Joynt GM, Wong KT, et allmpact of severe acute respiratory syndrome (SARS) on pulmonary function, functional capacity and quality of life in a cohort of survivorsThorax 2005;60:401-409.
[34]. Batawi, S., Tarazan, N., Al-Raddadi, R. et al. Quality of life reported by survivors after hospitalization for Middle East respiratory syndrome (MERS). Health Qual Life Outcomes 2019;17:101.

[35]. Malen Hollmann, Olatz Garin, Mariana Galante, Montserrat Ferrer, Angela Dominguez, Jordi Alonso. Impact of Influenza on Health-Related Quality of Life among Confirmed (H1N1)2009 Patients. 2020;

[36]. Jeffrey A. Linder MD, MPH, Daniel E. Singer MD. Health related Quality of Life of Adults with Upper Respiratory Tract Infections. Journal of General Internal Medicine 2003; 18(10).

[37]. https://www.who.int/healthinfo/survey/whoQoLqualityoflife/en/

[38]. https://www.cdc.gov/hrQoL/concept.htm

[39]. Deshpande PR, Rajan S, Sudeepthi B L, Abdul Nazir C P. Patient-reported outcomes: A new era in clinical research. Perspect Clin Res 2011;2:137-44 https://www.cdc.gov/hrQoL/wellbeing.htm

[40].SF-12 health survey; https://www.researchgate.net /publication/291994160_How_to_score_SF12_items

[41]. Mohammed F. Islam, Joseph Cotler \& Leonard A. Jason (2020) Post-viral fatigue and COVID-19: lessons from past epidemics, Fatigue: Biomedicine, Health \& Behavior, 2020;8(2):61-69.

[42]. Betty Pfefferbaum, M.D., J.D., and Carol S. North, M.D., M.P.E.. Mental Health and the Covid-19 Pandemic. N Engl J Med 2020; 383:510-512.

\footnotetext{
How to cite this article:

Aditi Soman, Aditee Mangaonkar. Health-related Quality of Life (HRQoL) of Individuals from Pune city after 6 weeks of Mild and Moderate grade COVID-19 infection. Int J Physiother Res 2021;9(1):
} 